\title{
Co-Occurring Substance Use, PTSD, and IPV Victimization: Implications for Female Offender Services
}

\author{
Shari A. McKee \\ Waypoint Centre for Mental Health Care \\ N. Zoe Hilton \\ University of Toronto and Waypoint Centre for Mental Health \\ Care \\ Version Post-print/accepted manuscript \\ Citation McKee, S. A., \& Hilton, N. Z. (2017). Co-occurring substance use, \\ (published version) PTSD, and IPV victimization: Implications for female offender services. \\ Trauma, Violence, \& Abuse. Advanced online publication. \\ doi:10.1177/1524838017708782
}

\section{How to cite TSpace items}

Always cite the published version, so the author(s) will receive recognition through services that track citation counts, e.g. Scopus. If you need to cite the page number of the author manuscript from TSpace because you cannot access the published version, then cite the TSpace version in addition to the published version using the permanent URI (handle) found on the record page.

This article was made openly accessible by $U$ of $T$ Faculty. Please tell us how this access benefits you. Your story matters. 
Co-Occurring Substance Use, PTSD, and IPV Victimization:

Implications for Female Offender Services

\author{
Shari A. McKee \\ Waypoint Centre for Mental Health Care
}

N. Zoe Hilton

University of Toronto and Waypoint Centre for Mental Health Care

McKee, S. A., \& Hilton, N. Z. (2017). Co-occurring substance use, PTSD, and IPV victimization: Implications for female offender services. Trauma, Violence, \& Abuse. Advanced online publication. doi:10.1177/1524838017708782

\title{
Author Note
}

Shari A. McKee, Ph.D., Georgianwood Program for Concurrent Disorders and Waypoint Research Institute, Waypoint Centre for Mental Health Care. N. Zoe Hilton, Ph.D., Department of Psychiatry, University of Toronto; Waypoint Research Institute, Waypoint Centre for Mental Health Care.

We would like to thank Barna Konkoly-Thege and Della Saunders for helpful comments on a previous draft, and Sonja Dey and Courtney Duthie for administrative assistance.

Correspondence concerning this article should be addressed to Shari McKee, Ph.D., C.

Psych., Waypoint Research Institute, Waypoint Centre for Mental Health Care, 500 Church

Street, Penetanguishene, ON, L9M 1G3, Canada. Email: smckee@waypointcentre.ca. 


\begin{abstract}
The co-occurrence of substance use disorders (SUD) and post-traumatic stress disorder (PTSD) among women who have been the victims of intimate partner violence (IPV) is complex and causal associations cannot be assumed. Although the presence of co-occurring disorders among IPV victims is a well-established research finding, there is a need for improved understanding of their prevalence and related mental health treatment requirements among female offenders. We review research indicating that service providers working with IPV victims can expect to encounter women with extensive concurrent problems and examine evidence for integrated treatment for substance use disorder, PTSD, and IPV. We propose an outline for assessing and treating SUD and PTSD among female offenders who have experienced IPV victimization. We intend this review to build on previous calls in the co-occurring disorders literature and help integrate the research and treatment evaluation literatures in a way that points to practical implications for policy and practice in female offender services.
\end{abstract}


Co-Occurring Substance Use, PTSD, and IPV Victimization:

Implications for Female Offender Services

There has been extensive research observing the co-occurrence of substance use disorders (SUD) and post-traumatic stress disorder (PTSD) among women who have been the victims of intimate partner violence (IPV). Our aim in this article is to review current evidence for cooccurring substance use and PTSD, and their treatment, among female victims of IPV. We will focus this review on women in the criminal justice system to highlight implications for correctional services for female offenders. In particular, we will discuss ways in which treatment recommendations for co-occurring SUD and PTSD could be administered in these settings.

\section{The Correctional Treatment Context}

In correctional settings, the dominant treatment model uses the Risk-Need-Responsivity (RNR) principles of offender intervention (e.g., Andrews \& Bonta, 2010). This service-based model asserts: first, that treatment services should be matched to the offender's risk level; second, that the reduction of risk requires treatment to be applied to criminogenic needs; and third, that treatment programs must be applied in a manner consistent with the offender's ability and learning style, with emphasis on cognitive-behavioral approaches and other effective treatments. RNR has not been widely adopted in the forensic psychiatric system, where intervention typically prioritizes mental health treatment and psychosocial recovery, particularly pharmacological therapy (e.g., Schaufenbil, Kornbluh, Stahl, \& Warburton, 2015).

There is evidence that the risk principle is appropriate for women as well as men (e.g., Geraghy \& Woodhams, 2015; Lovins, Lowenkamp, Latessa, \& Smith, 2007). For example, substance abuse is one of the “central eight” criminogenic needs (Andrews \& Bonta, 2010), and pre-imprisonment substance abuse has been reported by $50 \%$ or more of incarcerated women 
(e.g., Bloom, Owen \& Covington, 2003; Green, Miranda, Daroowalla \& Siddique, 2005; Lynch, Fritch, \& Heath, 2012). In Lynch and colleagues’ study of 102 incarcerated women, 72\% endorsed substance dependence criteria for the 12 months prior to incarceration, most commonly using methamphetamine (45\%). Similarly, Green and colleagues reported that $72 \%$ of 100 female jail inmates reported recent use of an illicit substance and 32\% were assessed as having an alcohol problem. However, research describes different pathways for men and women entering the criminal justice system (e.g., Bloom et al., 2003) and studies suggest additional gender-specific treatment needs for female offenders that are not typically considered in assessment procedures developed for men (e.g., Van Voorhis, Wright, Salisbury, \& Bauman, 2010). These needs include family conflict, lifetime history of abuse, and poor mental health, which are among the treatment needs consistently (although not exclusively) identified among women (e.g., Rettinger \& Andrews, 2010).

With respect to history of abuse, in a quantitative analysis of the pathways to offending of 718 women in U.S. prisons, Brennen, Breitenbach, Dieterich, Salisbury, and Van Voorhis (2012) observed that $37 \%$ of the women self-reported extensive physical abuse in their lives, such that this was a characteristic of four of the eight pathways. Other studies have reported substantially higher rates of potentially traumatic experiences, including $71 \%$ of 100 women incarcerated in a Maryland correctional center reporting violence perpetrated by a husband, partner, or boyfriend (Green et al., 2005). Lynch, Fritch, et al. (2012) summarized the evidence as conservatively indicating that approximately $50 \%$ of all incarcerated women have experienced physical or sexual assault prior to being imprisoned, and that female offenders more often have histories of interpersonal violence victimization than male offenders. Self-reported history of abuse is one of 
the gender-specific factors (i.e., more common among women) most strongly associated with women's reoffending (Rettinger \& Andrews, 2010).

\section{Substance Use, PTSD, and IPV Victimization}

There is substantial research evidence of an association between substance use and IPV victimization among women (e.g., Cafferky, Mendez, Anderson, \& Stith, 2016; Devries et al., 2014). In one study of 3568 women in a random sample from subscribers to a U.S. health plan, the $7 \%$ who reported IPV victimization in the past year were substantially more likely to also report any kind of substance abuse than those who reported no lifetime IPV victimization, and recently victimized women had an almost six-fold increase in risk of substance abuse over neverabused women (Bonomi et al., 2009). Similar results were reported for cocaine use in clinical and community samples (deDios, Anderson, Caviness, \& Stein, 2014; Feingold \& Capaldi, 2014). In their meta-analysis, Devries and colleagues (2014) found a small positive association between IPV and subsequent alcohol use (binge drinking or regular use) in five studies that met criteria for study quality. The odds of alcohol use subsequent to prior victimization was 1.25 overall; however, follow-up studies that controlled for alcohol use at Time 1 reported no statistical association between IPV and alcohol use measured at Time 2 (Devries et al., 2014).

Thus, although it is evident that female IPV victims exhibit more substance abuse problems than nonvictims, the temporal associations are not well understood, and causal relationships cannot be assumed. Adding to the complexity of the association between substance use and IPV victimization is the differences among substances of choice (e.g., alcohol compared with other drugs), the extent of consumption, and the additional risks presented by the use of multiple substances. For example, drug use has a stronger association with victimization than has alcohol use, and measures of substance use problems or dependency are more strongly 
associated than simple frequency of use (Cafferky et al., 2016). In their meta-analytic review, Cafferky and colleagues observed that research studies typically do not compare alcohol with other drugs and often do not specify the drug type. In this review, we will state the substance in question wherever possible.

Most women who seek substance use treatment have experienced some form of IPV and, in one study, 18\% reported severe victimization (i.e., using a knife or gun, punching or hitting with something that could hurt, choking, slamming against a wall, beating up, burning, or kicking; Kraanen, Vedel, Scholing, \& Emmelkamp, 2014). The rate of victimization is higher among women than men, as illustrated by Fernandez-Montalvo, López-Goñi, and Arteaga’s (2015) finding that $80 \%$ of women and $30 \%$ of men seeking outpatient treatment for drug addiction reported being a victim of psychological, physical, or sexual abuse. With respect to IPV specifically, Macy, Renz, and Pelino (2013) reported that at one university-affiliated substance abuse treatment program, 77 of 109 women (71\%) entering treatment in one year reported lifetime partner violence, and 31 (28\%) felt unsafe with their current partner. One cocaine user escaped IPV by gaining a new source of cocaine apart from her abusive partner, an experience that highlights the complexity of concurrent victimization and substance use.

As with IPV and substance use, the association of PTSD and IPV victimization is both prevalent and complex (e.g., Kuijpers, van der Knaap, \& Winkel, 2012; Seedat, Stein, \& Forde, 2005; Yalch, Levendosky, Bernard, \& Bogat, 2015). Among battered women residing in shelters, about 70\% meet diagnostic criteria for current PTSD (Johnson \& Zlotnick, 2007; Peterson, 2013). In one study, trauma symptoms distinguished recent IPV victims residing in the community from those in a shelter (Galano, Hunter, Howell, Miller, \& Graham-Bermann, 2013). PTSD was the most common mental illness diagnosed using clinical interviews in a community 
sample of female IPV victims, being identified among 57\% of the 94 women interviewed, and it co-occurred with depression in $45 \%$ of the women and with alcohol dependence in $12 \%$ (Nathanson, Shorey, Tirone, \& Rhatigan, 2012). IPV could meet the DSM-5 Criterion A requirement for the diagnosis of PTSD, which includes actual or threatened death, serious injury or sexual violence, either through direct experience, witnessing it happen to someone else, or through learning that it happened to family members or close friends. Indeed, greater PTSD symptomatology among women in the community and shelters has been linked to psychological abuse, sexual coercion, physical abuse severity, and injury (e.g., Dutton, 2009; Messing, Thaller, \& Bagwell, 2014; Nathanson et al., 2012; Perez, Johnson, \& Wright, 2012).

Finally, there is evidence that substance use is associated with increased PTSD symptomatology among female IPV victims. For example, among 212 women in the community experiencing IPV in the previous six months, those who used drugs reported higher PTSD severity scores than women reporting no substance use or alcohol use only, and specifically reported more avoidance and numbing symptoms compared to alcohol users, and more arousal symptoms compared to nonusers (Sullivan \& Holt, 2008). Trauma appears to increase alcohol craving (Nosen, Littlefield, Schumacher, Stasiewicz, \& Coffey, 2014), and among 41 women experiencing IPV in a community sample and providing reports for a period of 21 days, those who met criteria for PTSD were nearly 15 times more likely to have days in which they used both alcohol and drugs (Sullivan et al., 2016).

Not surprisingly, increased PTSD and other problems are found among women seeking support for IPV (e.g., Johnson \& Zlotnick, 2007; Seedat et al., 2005), raising expectations that IPV victims residing in shelters represent a complex picture of comorbid problems. However, according to one study of victims in two shelters, a minority of women used services other than 
the shelters and recourse to the criminal justice system; 22\% had accessed psychotherapy overall, with significantly lower rates among such service use for women identified as African American (16\%) than White women (30\%; Johnson \& Zlotnick, 2007). A U.S. national survey of 325 professionals working with IPV victims found that $84 \%$ believed these women often had symptoms of mental health and substance use problems, and 88\% felt their agency should screen for these problems, yet only 14\% of agencies did (Simmons, Whalley, \& Beck, 2014).

\section{Substance Use, PTSD, and IPV Victimization among Female Offenders}

A similar pattern of co-occurring problems is revealed in studies of female offenders. Mental illness is prevalent among both men and women involved in the criminal justice system, especially among those who use substances (e.g., Peters, Wexler, \& Lurigio, 2015; Sacks, 2004). PTSD especially is a concern among women; for example, among 253 female inmates in a large U.S. jail, 35\% reported trauma-related symptoms (Scott, Dennis, \& Lurigio, 2015) and $45 \%$ of 387 women in a U.S. maximum security state prison met the criteria for a diagnosis of PTSD, also based on a self-report assessment (Harner, Budescu, Gillihan, Riley, \& Foa, 2015). PTSD is related to IPV victimization in custodial populations (i.e., offenders in correctional institutions, jails, and prisons). For example, Meyer and colleagues (2013) reported that, among $84 \mathrm{HIV}$-infected women in jail, those reporting IPV victimization were significantly more likely to meet criteria for PTSD or be suicidal. Specifically, 24\% of women who reported IPV experienced PTSD compared with 16\% of other women. Furthermore, among 102 women incarcerated in a Northwestern U.S. prison, 22\% met diagnostic criteria for PTSD based on selfreport, and PTSD symptoms were higher among the 90 women who experienced IPV (effect size .05; Lynch, Fritch, et al., 2012); experiencing multiple forms of IPV (e.g., physical and sexual) was also associated with increased PTSD symptoms (effect size .11). 
Co-occurring disorders among female offenders are also associated with histories of trauma (Scott et al., 2015). For example, Minieri and colleagues (2014) reported that, in a sample of over 300 women incarcerated in one of four U.S. states who used substances at least once a week prior to incarceration, self-reported IPV victimization prior to incarceration was associated with a higher rate of depression, anxiety, suicidal thoughts and other symptoms of mental illness (main effect size .15) as reported on a clinical research questionnaire.

Research with female offenders indicates that those with co-occurring SUD and mental disorders are at increased risk of relapse to substance use when compared to those with SUD only. For example, none of the 24 women without PTSD but $17 \%$ of the 36 women with PTSD recorded at least one positive drug screen after treatment (Kubiak, 2004). The co-occurrence of SUD and PTSD can be complicated by a multitude of additional problems. Classifying 404 female probationers and parolees into three groups according to overall measures of psychological distress including mood, anxiety, and psychotic disorder symptoms, Golder, Engstrom, Hall, Higgins, and Logan (2015) reported that women in the highest distress group had the highest rates of regular use of alcohol to intoxication (70\% vs. $52 \%$ of other groups). High distress was also associated with increased reports of PTSD, IPV, and other victimization, indicating the inter-relation of all three phenomena with additional mental health problems.

\section{Theory of Associations among PTSD and Co-Occurring Problems}

This inter-relation of PTSD, substance use and other comorbid disorders is difficult to understand and untangle, both empirically and conceptually (e.g., Lockwood \& Forbes, 2014). Attempts to theoretically explain their associations have been developed in order to guide intervention. Existing theories of the co-occurrence of PTSD and SUD focus on three main hypothesized mechanisms (e.g., van Dam, Vedel, Ehring, \& Emmelkamp, 2012). The "high 
risk” hypothesis is that substance use occurs first and places the individual at high risk of exposure to potentially traumatic events. That is, the lifestyle that is often associated with acquiring, using, and recovering from substances may involve several high risk behaviours as well as substantial time spent in dangerous environments, increasing the chance of exposure to traumatic events and the development of PTSD.

The "shared vulnerability" hypothesis posits that both PTSD and SUD are explained by a mechanism, unidentified as yet, that increases the likelihood of disturbed reactions to adverse events. Promising explanations include biological mechanisms such as genetic variants, neuroendocrine dysregulation, or the neurotransmitter cycles associated with arousal and reward systems (e.g., Norman et al., 2012).

In contrast, the "self-medication” hypothesis posits that trauma survivors use substances to ease PTSD symptoms. By this reasoning, PTSD symptoms come to trigger craving for substance use, and withdrawal symptoms can evoke further PTSD symptoms (e.g., van Dam et al., 2012). This hypothesis is currently the most widely accepted. Evidence that PTSD more often precedes SUD than vice versa and that patients express a functional relationship between the two (e.g., Lockwood \& Forbes, 2014; van Dam et al., 2012) is consistent with this view. More recently a “unitary” theory was proposed by Dell’Osso and colleagues (2014). This theory is based on empirical associations between the severity of opioid addiction and PTSD symptom domains. It incorporates evidence of neurobiological similarities and increasing sensitivity to stressful life events throughout the course of substance use, suggesting that PTSD may be part of the psychopathology of addiction. These existing theories point to the need for the prioritizing or integration of SUD treatment for women presenting with both SUD and PTSD. 
Theoretical explanations that incorporate PTSD, SUD, and IPV victimization remain to be developed. IPV could be an unidentified third factor increasing traumatic reactions and substance use in response to other adverse events, or it could be the life-threatening experience meeting the criterion for a traumatic event in the diagnosis of PTSD. Alternatively, IPV could be a compounding factor in PTSD that increases the likelihood of self-medication. Our suggestions for integrated treatment for female offenders with IPV victimization will, therefore, draw on the following evidence from clinical interventions largely focusing on PTSD and SUD.

\section{Integrating Treatment for PTSD, SUD, and IPV Victimization}

In their meta-analysis of substance abuse treatments, Fowler and Faulkner (2011) found that IPV victims appeared to benefit more than other women when participating in a traumafocused substance use intervention, at least initially. Kail (2010) recommended using motivational interviewing (MI; Miller \& Rollnick, 2013) for IPV victims with problematic substance use, and among female offenders MI helped reduce substance-related risk-taking behaviors (Weir et al., 2009). Warshaw, Sullivan, and Rivera’s (2013) review of trauma-focused interventions for IPV victims identified nine studies referencing eight distinct interventions, often developed in consultation with IPV experts, advocates, and survivors. Many interventions were modified cognitive-behavioral therapy protocols that addressed issues specific to IPV, such as trauma-related guilt, psychoeducation about IPV, safety needs, past trauma histories, ongoing contact with the abuser, empowerment, and risk of subsequent victimization. The authors concluded that these interventions hold promise for reducing some PTSD and depression symptoms, but that more research is needed. More recently, Cognitive Trauma Therapy (CTT) with IPV victims that focused on reducing trauma-related guilt has demonstrated positive effects on PTSD and other mental health problems (Beck et al., 2016), with effects maintained at follow 
up (Allard, Norman, Thorp, Browne, \& Stein, 2016). CTT is a manualized cognitive behavioral therapy designed specifically for female victims of IPV that includes trauma history exploration and exposure to trauma reminders, stress management, PTSD education, assertiveness training, managing mistrust, identifying potential abusers, managing contacts with former partners, managing anger, decision-making, and overcoming trauma-related guilt.

Evidence-based recommendations for co-occurring SUD and mental illness treatment have been reviewed extensively elsewhere (e.g., McKee, 2017). For the remainder of this section we will focus specifically on integrated treatment for SUD and PTSD, and efforts to integrate these treatments with services for IPV victims.

An integrated approach targeting multiple treatment needs at once would seem to be most efficient for addressing the comorbidity of IPV, PTSD, and SUD (e.g., Dass-Brailsford \& Myrick, 2010; Ritter, Kivisto, Handsel, \& Moore, 2014). This view is based not only on the extensive evidence of comorbidity but also on findings from treatment evaluations such as baseline PTSD predicting post-treatment substance use relapse (e.g., Brown, 2000; Kubiak, 2004) and trauma-focused therapy having benefits for substance use (e.g., Nosen et al., 2014). Furthermore, studies have found that integrated treatment for SUD and mental illness is more effective than parallel (i.e., SUD and mental illness are treated simultaneously but by different providers with no coordination) or sequential treatment (e.g., Barrowclough et al., 2001; Dixon et al., 2010; Drake, O’Neal, \& Wallach, 2008; Ziedonis et al., 2005). Integrated treatment also avoids other disadvantages of non-integrated services, including unnecessary organizational and administrative barriers and higher service costs (Mueser, Noordsy, Drake \& Fox, 2003). McKee, Harris, and Cormier (2013) showed that offering integrated treatment (including weekly CBT and Seeking Safety groups) for participants with co-occurring mental illness and SUD was 
associated with improved mental health, acquisition of relevant skills and knowledge, improvement in self-esteem, and also led to strong satisfaction with the program.

Seeking Safety is the most researched integrated approach to treating both substance abuse and trauma (e.g., Najavits, 2009). It is a present-focused, manualized, cognitive behavioral treatment that provides psychoeducation and coping skills training in 25 group or individual sessions. Seeking Safety was the first treatment model to show improvement over comparisons in both PTSD symptoms and substance abuse outcomes in randomized or controlled trials (Najavits \& Hien, 2013). There is also evidence that it can be feasibly offered to women in prison, where its completion was associated with reductions in women meeting the criteria for PTSD and in self-reported substance use at 6-weeks and 3-month follow-ups post-release (Zlotnick, Najavits, Rohsenow, \& Johnson, 2004; see also Barrett et al., 2015). Seeking Safety is a first-stage trauma treatment which teaches safe-coping skills, such as setting boundaries in relationships, grounding techniques, creating safety, asking for help, and compassion. One study examined IPV outcomes for women with PTSD and SUD who attended Seeking Safety versus a psychoeducational group (Cohen, Field, Campbell, \& Hein, 2013). Although there was no main effect of treatment condition, women who were abstinent at baseline and in the 12-session Seeking Safety group reported significantly less IPV one year later. The authors suggested that women in recovery from substance use are perhaps more able to benefit from the cognitivebehavioral strategies taught in the Seeking Safety curriculum. In this study, women were more likely to report IPV at follow up if they were living with someone with an alcohol problem, had more lifetime exposure to traumatic events, and had reported recent physical or sexual assault. Some studies have not shown that Seeking Safety is superior to alternative interventions. Hermann, Hamblen, Bernardy, and Schnurr (2014) reviewed the empirical support for Seeking 
Safety and concluded that there is inconsistent evidence about whether its effectiveness at reducing PTSD, SUD, or both, is superior to comparison treatments, such as standard community and residential addiction treatment, which typically included case management, self-help group facilitation, psychoeducation, anger management, cognitive-behavioral groups, and psychopharmacology. They suggested that the evidence is stronger for individual treatments for PTSD and SUD than for the integrated models, notwithstanding that some studies involved only a portion of the recommended 25 Seeking Safety sessions, thus testing partial doses of the intervention. A subsequent meta-analytic review of PTSD and SUD treatments using only randomized controlled trials (RCT) concurred, reporting positive effects for psychosocial interventions incorporating trauma-focused intervention alongside SUD intervention (standardized mean differences in PTSD severity and substance use at post-treatment or up to 7 months later ranged from -.13 to -.41; Roberts, Roberts, Jones, \& Bisson, 2015). These effects were larger than those for non-trauma focused interventions, but the available evidence was graded as being low or very low quality. Similarly, the American Psychological Association's draft guidelines for PTSD treatment state there is insufficient evidence to recommend for or against Seeking Safety (APA, 2016).

Meanwhile, Ritter et al. (2014) suggested combining Seeking Safety with other evidencebased treatments, such as exposure therapy and cognitive processing therapy (CPT; Resick \& Schnicke, 1993). One such manualized intervention, Concurrent Treatment of PTSD and Substance Use Disorders Using Prolonged Exposure (COPE; Mills et al., 2012), combines exposure therapy for PTSD with cognitive-behavioral and psycho-educational interventions for SUD and PTSD in 13 sessions. In an RCT of 103 participants with PTSD and substance dependence, patients receiving either COPE or the usual treatment (access to counseling, 
detoxification, residential rehabilitation, and pharmacotherapy) showed significant improvements in PTSD symptoms from baseline to nine-month follow-up, but COPE resulted in greater improvements in PTSD than the usual treatments alone. Both groups showed significant reductions in severity of substance dependence with no significant differences between groups. Exposure therapy did not increase the COPE group's severity of substance dependence, showing that exposure can be beneficial even when participants are not abstinent from substances.

There is little comparable work that specifically addresses women's experience of IPV victimization. Collaborative treatment provision using cross-referral among services has been recommended for domestic violence shelter services, focusing on safety before sobriety (e.g., Macy \& Goodbourn, 2012). The Helping Women Recover Program (Covington, 1999, cited in Dass-Brailsford \& Myrick, 2010) is a shelter-based treatment intervention for substance abuse that combines trauma and addiction treatment using a CBT, relational theory, and expressive arts approach. The Women, Co-Occurring Disorders, and Violence Study (WCDVS; Morrissey et al., 2005) was the first major coordinated attempt to address the treatment needs of women with co-occurring mental illness and SUDs and a history of physical or sexual abuse. The quasiexperimental study was conducted for a period of three years and at nine treatment sites, each providing one of four manualized integrated treatment interventions. Overall, the study found improvements on trauma and mental health symptoms but no effect on subsequently reported substance use (Morrissey et al., 2005).

\section{Integrated Treatment for Female Offenders with IPV Victimization}

As this review of the treatment literature has shown, there is some evidence for several treatment options for women with SUD, PTSD, and IPV victimization. Applying these findings to women in corrections could invoke a "gender-informed responsivity principle” (Blanchette \& 
Brown, 2006, p. 126). This approach would involve the creation of a treatment environment that provides safety, respect, and dignity as well as a context in which SUD and PTSD can be addressed in an integrated fashion (e.g., Covington \& Bloom, 2006). Evidence from goodquality follow-up studies now indicates that gender-informed interventions are associated with greater reductions in recidivism than gender-neutral interventions (Gobeil, Blanchette, \& Stewart, 2016). Correctional services for women, however, are rarely designed to match genderspecific treatment needs; indeed, specific concerns appear rarely identified in the criminal justice system, even at specialized services such as domestic violence courts (e.g., Riger, Bennett, \& Sigorvinsdottir, 2014).

There has been a call for integrated treatment services for criminal justice-involved individuals (Mahoney, Chouliara, \& Karatzias, 2015); however, few such programs are available in the criminal justice system (e.g., Sacks, 2004). Whereas offenders with co-occurring mental health disorders and SUD may have access to substance use treatment, fewer receive behavioral or mental health treatment (e.g., Scott et al., 2015). Nowotny, Belknap, Lynch and DeHart (2014) reported that one-third of 104 women in jail in U.S. Appalachian states with co-occurring mental illness and substance abuse had received no treatment, and only $29 \%$ received treatment for both problems (including self-help groups, counseling, or medication). The realization of a systematic approach to offender care continues to present challenges. Correctional settings often do not screen for co-occurring mental illness or SUD, and access to specialized services for these issues is rare (MacDonald, 2013). In addition, many of the offender treatment models have been developed based on male correctional populations, and do not take into account important differences of female offenders such as higher prevalence of trauma and abuse, higher psychiatric co-morbidity, and the explanatory role of substance misuse in violent and other 
offending behavior (Covington, Burke, Keaton, \& Norcott, 2008; de Vogel \& Nicholls, 2016). Female offenders themselves have been reported to seek integrated treatment for trauma, substance use, and relationship problems, and see a need for licensed mental health professionals in prisons (e.g., Green et al., 2005; Lynch, Fritch, et al., 2012; Matheson, Brazil, Doherty, \& Forrester, 2015). There is no reason to expect that findings of the superiority of integrated treatment for co-occurring SUD and mental illness in non-offender populations would not be applicable to offenders.

Programs that have been designed for women with a gender-specific focus in mind are vulnerable to lapses in fidelity of implementation. For example, the “Moving On” program was devised specifically for women by the Iowa Department of Corrections in the late 1990s to respond to an increasing number of women under probation (Gehring, Van Voorhis, \& Bell, 2010). It was designed to use cognitive behavioral techniques to help women address patterns of behavior, emotional reactions, and experiences responsible for their criminal behavior. It encouraged awareness and change in eight modules: women in society, self-care, family, relationships, emotions, problem solving, assertiveness, and “moving on.” A follow up of 190 women who participated in the program compared with 190 women matched on district, race, age, risk category, and probationary time, who did not participate in any cognitive-behavioral program during the same time, showed that participants had fewer arrests and convictions (Gehring et al., 2010). However, the program duration was later reduced by one third, essential components such as skill building and homework were omitted, class sizes were increased, and participation became mandatory. These changes were associated with reduced effectiveness (Duwe \& Clark, 2015). The importance of program fidelity extends not only to treatment 
services, but also risk assessment, rehabilitation planning, and staff training (e.g., Wright, Van Voorhis, Salisbury, \& Bauman, 2012).

An example of a gender-specific approach for women in the justice system was described by Sacks and colleagues (2008). This prison-based Therapeutic Community (TC) for women showed promising improvements in mental health, criminal behavior, and other outcomes. Sacks and colleagues compared a TC that included several groups (e.g., Seeking Safety, relationships, parenting skills, relapse prevention, and relating female roles and relationships to substance use) to a standard, cognitive-behavioral control program, which focused on relapse prevention and recidivism. The key modifications made to the TC for women included a focus on mutual respect in place of authoritarianism to avoid repeating past abusive relationships, and a hierarchy that allowed for opportunity to practice leadership, exercising authority in a positive way and being a positive role model. Six months after release, women in both groups showed significant improvements on all outcome variables, and the women in the TC showed significantly better outcomes in mental health, trauma exposure, and criminal behavior. Salisbury (2015) observed that a “gender-responsive” approach to correctional treatment is considered by many to be contrary to evidence about treating criminogenic needs. The accumulated evidence of the inter-relation of substance abuse, PTSD, and IPV victimization reviewed in this article, however, suggests that a paradigm change in treatment for female offenders can be empirically supported. Whereas some see promise in programs for women that include IPV services but omit SUD treatment, which is considered gender neutral (e.g., Holtfreter \& Wattanaporn, 2014), we concur with Wright and colleagues (2012) and others (e.g., Scott et al., 2015) that evidence-based therapeutic approaches to substance abuse, victimization, and trauma-informed treatment should be further developed and evaluated. 


\section{Proposed Model}

Based on our review of supported treatments for IPV, SUD and PTSD, and evidence that these problems are likely to be particularly prominent among female offenders, we now propose a therapeutic approach that combines assessment with staged, integrated care for women in correctional or forensic services. The need to prioritize safety for IPV victims and to support these women to be able to participate in other therapies leads us to embed our suggestions within Judith Herman's three-stage model of trauma recovery (Herman, 1992). Stage 1 of Herman’s model, Safety and Stabilization, has a focus on safety from PTSD symptoms and retraumatization through the use of coping skills. Women learn skills to help regulate difficult emotions and are encouraged to seek out safe living environments and safe interpersonal support networks. Stage 2, Remembrance and Mourning, involves reconstructing the trauma story so that the woman can process and make sense of the traumatic events. This stage is best addressed once basic safety has been established, and ongoing monitoring of safety and stability during this stage is recommended. Stage 3, Reconnection, involves the creation of a new sense of self in the context of meaningful relationships and activities. In this stage, a woman recognizes the impact that trauma has had on her life and takes steps to move forward and create meaning and joy in her life (Herman, 1992). Our proposed model has four steps.

\section{Step 1: Pre-Treatment: Assessment}

Currently the Level of Service Inventory - Revised (LSI-R; Andrews \& Bonta, 2001) or a similar assessment is commonly used for offenders upon entry to the correctional system. The LSI-R is a validated tool for identifying offenders’ risk of recidivism and criminogenic needs and is useful for treatment planning and assigning supervision levels. The LSI has been shown to be one of the best tools for predicting recidivism in female offenders (de Vogel \& Nicholls, 2016). 
Particularly useful elements for incarcerated women include the assessment of substance use and criminal companions as criminogenic needs. Once identified, a case can be made to prioritize these needs for treatment intervention.

In addition to the LSI-R or other routine offender assessment, we recommend tools specifically to screen for and assess IPV, SUD and PTSD as necessary first steps to identify cooccurring problems. Such assessments should be repeated at regular intervals for women who demonstrate relevant symptoms and histories. The Conflict Tactics Scales - Revised (CTS2; Straus, Hamby, Boney-McCoy, \& Sugarman, 2006) is a well-researched tool designed to capture the frequency of various acts of psychological, physical, or sexual aggression and injury. It can be scored reliably and has sound test metrics. Prefacing items with "Not including horseplay or joking around” might reduce false positives (Hamby, 2016). A brief tool with some research supporting its psychometric properties is the Woman Abuse Screening Tool (e.g., Brown, Lent, Schmidt, \& Sas, 2000), which additionally captures women’s emotional reactions. IPV screening can be done by interview, self-report questionnaire, or computer-assisted administration. The latter does not require extensive training and might increase identification of IPV relative to clinician interview (Hussain et al., 2015; O’Doherty et al., 2014). A further component of assessment for IPV victims is evaluation of the risk of further violence, usually with respect to a particular intimate partner. Risk assessment can be based on a victim interview using a tool such as the Danger Assessment (e.g., Campbell, Webster, \& Glass, 2009) or Ontario Domestic Assault Risk Assessment (ODARA; Hilton, Harris, \& Rice, 2010), but a criminal record check of the perpetrator is recommended for a more thorough assessment.

For SUD, brief screeners are widely available, such as the AUDIT (Alcohol Use Disorders Identification Test; Saunders, Aasland, Babor, dela Fuente, \& Grant, 1993), the DAST 
(Drug Abuse Screening Test-10; Skinner, 1982), or the CAGE-AID (Brown \& Rounds, 1995). The Addiction Severity Index (ASI; McLellan, Luborsky, Woody, \& O’Brien, 1980) or the Structured Clinical Interview for DSM-5-SUD module (First, Williams, Karg, \& Spitzer, 2015) can be used by trained providers for a more in-depth assessment of substance use. For PTSD screening, a brief, validated instrument, such as the PCL-5 (Posttraumatic Stress Disorder Checklist for DSM-5; Weathers, Litz, et al., 2013), or the Short Screening Scale for PTSD (Breslau, Peterson, Kessler, \& Schultz,1999) can be used by a variety of treatment providers. For more thorough assessment, the CAPS-5 (Clinician-Administered PTSD Scale for DSM-5; Weathers, Blake, et al., 2013) remains the accepted standard.

\section{Step 2: Seeking Safety}

For IPV victims with SUD and PTSD, we suggest offering weekly Seeking Safety as a first-stage treatment in a group format. This intervention offers helpful psychoeducation and teaches coping skills that can be used for both PTSD and SUD. It has the advantage of being well-researched, integrated, manualized, and is generally well-received by participants. One

study of Seeking Safety for incarcerated women reported small improvements in PTSD (Lynch, Heath, Mathews, \& Cepeda, 2012). Particularly useful for the correctional or forensic setting is that Seeking Safety can be delivered by a wide variety of helping professionals, and although some training is recommended, training is offered frequently across the U.S. and Canada. Participants should be assessed following completion of the Seeking Safety intervention to determine whether symptoms of PTSD have improved. If symptoms persist, we suggest that treatment should continue to Step 3.

\section{Step 3: Exposure and Cognitive-Behavioral Treatments}


Women who continue to endorse substantial PTSD symptoms should be offered more focused, individual trauma treatment. This will require having more clinically educated staff who are trained in individual exposure-based, CTT, or CPT interventions, and may require sensitivity to the potentially triggering environment of the custodial institution. Women who endorse strong urges to use, or who continue to use substances whether in custody or under community supervision, should be offered MI and structured relapse prevention skills, including how to identify triggers, ways to cope with cravings, and drug-refusal skills (e.g., Herie \& WatkinMerek, 2006). For women continuing violent intimate relationships in the community or maintaining a relationship with an abusive partner while incarcerated, increasing awareness of power in one's relationships and recognition of equality in a healthy relationship (e.g., Minieri et al., 2014) could be combined with structured interventions with specific psychoeducation and advocacy components, such as those reviewed by Warshaw and colleagues (2013). In addition, learning general CBT skills, such as the use of thought records, action plans, and behavioral experiments could help all women cope with a wide variety of issues, including PTSD and SUD, as they arise (e.g., Greenberger \& Padesky, 2016).

\section{Step 4: Reconnection}

For women who are able to achieve safety and progress to an amelioration of symptoms of PTSD and SUD, and who are approaching release or already under community supervision, the focus should shift to reconnection with safe and supportive family members, the 12-step community, IPV and mental health supports, as well as to healthy activities, such as employment and parenting tasks. Currently, treatment services designed to help offenders as they transition from institution to community are rare but promising, as demonstrated by experimental treatments for male offenders with co-occurring mental health and substance use disorders (e.g., 
Sacks, Chaple, Sacks, McKendrick, \& Cleland, 2012). Providers can help women identify their goals, and help them gain skills and plan for activities that will reduce their risk of association with abusive partners or other criminal associates.

The above model outlines ways in which treatment recommendations for co-occurring SUD and PTSD could be administered in correctional settings for female offenders. We hope these suggestions will encourage the development of integrated treatment for IPV victims with co-occurring disorders and promote research identifying the benefits and limits of integrated treatment for female offenders.

\section{Conclusion}

There is ample accumulated evidence for the increased risk of co-occurring substance use and PTSD among female IPV victims, including female offenders. There is also an existing evidence base for interventions to address these problems, including integrated treatments that can be offered in a correctional or forensic setting, and a growing movement supporting genderresponsive interventions for female offenders. Based on our review of the research and treatment literatures (whose key findings are summarized in Table 1), we have made suggestions for an integrated treatment model for SUD, PTSD, and IPV victimization among female offenders and identified related practice needs (summarized in Table 2). We are hopeful that the emerging trend for assessing and treating these co-occurring problems within the RNR model will continue to expand and reach more women whose multiple sources of distress have previously been overlooked. As more and larger scale interventions are offered, they will also provide opportunities for further evaluations and meta-analysis of treatment effectiveness. 


\section{References}

Allard, C. B., Norman, S. B., Thorp, S. R., Browne, K. C., \& Stein, M. B. (2016). Mid-treatment reduction in trauma-related guilt predicts PTSD and functioning following cognitive trauma therapy for survivors of intimate partner violence. Journal of Interpersonal Violence. Advanced online publication. doi:10.1177/0886260516636068

Andrews, D. A., \& Bonta, J. (2010). The psychology of criminal conduct (5th ed.). Newark, NJ: Lexis Nexis.

APA. (2016). Clinical practice guideline for the treatment of posttraumatic stress disorder (PTSD) in adults, Draft October 4, 2016. Retrieved from http://apacustomout.apa.org/commentPracGuidelines/Practice/Full\%20PTSD\%20text\%2 0clean\%2010-4-16\%20revised.pdf

Barrett, E. L., Indig, D., Sunjuc, S., Sannibale, C., Sindicich, N., Rosenfeld, J., ... \& Mills, K. (2015). Treating comorbid substance use and traumatic stress among male prisoners: A pilot study of the acceptability, feasibility, and preliminary efficacy of Seeking Safety. International Journal of Forensic Mental Health, 14, 45-55. doi:10.1080/14999013.2015.1014527

Barrowclough, C., Haddock, G., Tarrier, N., Lewis, S., Morning, J., Obrien, R., ... McGovern, J. (2001). Randomized controlled trial of motivational interviewing, cognitive behavior therapy, and family intervention for patients with comorbid schizophrenia and substance use disorders. American Journal of Psychiatry, 158, 1706-1713. doi:

\subsection{6/appi.ajp.158.10.1706}


Beck, J. G., Tran, H. N., Dodson, T. S., Henschel, A. V., Woodward, M. J., \& Eddinger, J. (2016). Cognitive Trauma Therapy for battered women: Replication and extension. Psychology of Violence, 6, 368-377. doi:10.1037/vio0000024

Blanchette, K., \& Brown, S. L. (2006). The assessment and treatment of women offenders: An integrative perspective. Chichester, UK: Wiley.

Bloom, B., Owen, B., \& Covington, S. (2003). Gender-responsive strategies: Research, practice, and guiding principles for women offenders. Unpublished report, National Institute of Corrections. Retrieved from http://static.nicic.gov/Library/018017.pdf

Bonomi, A. E., Anderson, M. L., Reid, R. J., Rivara, F. P., Carrell, D., \& Thompson, R. S. (2009). Medical and psychosocial diagnoses in women with a history of intimate partner violence. Archives of Internal Medicine, 169, 1692-1697. doi:

10.1001/archinternmed.2009.292

Brennen, T., Breitenbach, M., Dieterich, W., Salisbury, E. J., \& Van Voorhis, P. (2012). Women’s pathways to serious and habitual crime: A person-centered analysis incorporating gender responsive factors. Criminal Justice and Behavior, 9, 1481-1508. doi:10.1177/0093854812456777

Breslau, N., Peterson, E. L., Kessler, R. C., \& Schultz, L. R. (1999). Short screening scale for DSM-IV post-traumatic stress disorder. American Journal of Psychiatry, 156, 908-911.

Brown, P. J., (2000). Outcome in female patients with both substance use and post-traumatic stress disorders. Alcoholism Treatment Quarterly, 18, 127-135.

Brown R.L. \& Rounds, L.A. (1995). Conjoint screening questionnaires for alcohol and other drug abuse: Criterion validity in a primary care practice. Wisconsin Medical Journal, 4, 135-40. 
Brown, J. B., Lent, B., Schmidt, G., \& Sas, G. (2000). Application of the woman abuse screening tool (WAST) and WAST-short in the family practice setting. Journal of Family Practice, 49, 896-903.

Cafferky, B. M.,Mendez, M., Anderson, J, R., Stith, S. M. (2016). Substance use and intimate partner violence: A meta-analytic review. Psychology of Violence. Advanced online publication. doi:10.1037/vio0000074

Campbell, J. C., Webster, D. W., \& Glass, N. (2009). The Danger Assessment: Validation of a lethality risk assessment instrument for intimate partner femicide. Journal of Interpersonal Violence, 24, 653-674. doi:10.1177/0886260508317180

Cohen, L. R., Field, C., Campbell, A. N., \& Hein, D. A. (2013). Intimate partner violence outcomes in women with PTSD and substance use: A secondary analysis of NIDA clinical trials network “Women and Trauma” multi-site study. Addictive Behaviors, 38, 2325-2332. doi:10.1016/j.addbeh.2013.03.006

Covington, S. S., \& Bloom, B. E. (2006). Gender responsive treatment and services in correctional settings. Women \& Therapy, 29, 9-33. doi:10.1300/J015v29n03_02

Covington, S.S., Burke, C., Keaton, S., \& Norcott, C. (2008). Evaluation of a trauma-informed and gender-responsive intervention for women in drug treatment. Journal of Psychoactive Drugs, 5, 387-398. doi:10.1080/02791072.2008.10400666

Dass-Brailsford, P., \& Myrick, A. C. (2010). Psychological trauma and substance abuse: The need for an integrated approach. Trauma, Violence, \& Abuse, 11, 202-213. doi: $10.1177 / 1524838010381252$ 
deDios, M. A., Anderson, B. J., Caviness, C. M., \& Stein, M. (2014). Intimate partner violence among individuals in methadone maintenance treatment. Substance Abuse, 35, 190-193. doi:10.1080/08897077.2013.835764

Dell’Osso, L., Ruganib, F., Maremmani, A. G. I., Bertoni, S., Pani, P. P., \& Maremmani, I. (2014). Towards a unitary perspective between Post-Traumatic Stress Disorder and Substance Use Disorder: Heroin use disorder as case study. Comprehensive Psychiatry, 55, 1244-1251. doi:10.1016/j.comppsych.2014.03.012

De Vogel, V., \& Nicholls, T.L. (2016). Gender matters: An introduction to the special issue on women and girls. International Journal of Forensic Mental Health, 15, 1-25. doi: 10.1080/14999013.2016.1141439

Devries, K. M., Child, J. C., Bacchus, L. J., ... Heise, L. (2014). Intimate partner violence victimization and alcohol consumption in women: A systematic review and metaanalysis. Addiction, 109, 379 - 391. doi:10.1111/add.12393

Dixon, L. B., Dickerson, F., Bellack, A. S., Bennett, M., Dickinson, D., Goldberg, R. W., .. . Kreyenbuhl, J. (2010). The 2009 schizophrenia PORT psychosocial treatment recommendations and summary statements. Schizophrenia Bulletin, 36, 48-70. $\underline{\text { doi:10.1093/schbul/sbp115 }}$

Drake, R. E., O’Neal, E. L., \& Wallach, M. A. (2008). A systematic review of psychosocial research on psychosocial interventions for people with co-occurring severe mental and substance use disorders. Journal of Substance Abuse Treatment, 34, 123-138. doi:10.1016/j.jsat.2007.01.011

Dutton, M. (2009). Pathways linking intimate partner violence and posttraumatic disorder. Trauma, Violence, \& Abuse, 10, 211-224. doi:10.1177/1524838009334451 
Duwe, G., \& Clark, V. (2015). Importance of program integrity: Outcome evaluation of a gender-responsive, cognitive-behavioral program for female offenders. Criminology \& Public Policy, 14, 301-328. doi:10.1111/1745-9133.12123

Feingold, A., \& Capaldi, D. M. (2014). Associations of women's substance dependency symptoms with intimate partner violence. Partner Abuse, 5,152-167. doi: 10.1891/19466560.5 .2 .152

Fernandez-Montalvo, J., López-Goñi, J., \& Arteaga, A. (2015). Psychological, physical and sexual abuse in addicted patients who undergo treatment. Journal of Interpersonal Violence, 30, 1279-1298. doi:10.1177/0886260514539843

First, M.B., Williams, J.B.W., Karg, R.S., \& Spitzer, R.L. (2015). Structured clinical interview for DSM-5 disorders, clinician version (SCID-5-CV). Arlington, VA: American Psychiatric Association.

Fowler, D. N., \& Faulkner, M. (2011). Interventions targeting substance abuse among women survivors of intimate partner violence abuse: A meta-analysis. Journal of Substance Abuse Treatment, 41, 386-398.

Galano, M. M., Hunter, E. C., Howell, K. H., Miller, L. E., \& Graham-Berman, S. A. (2013). Predicting shelter residence in women experiencing recent intimate partner violence. Violence Against Women, 19, 518-535. doi:10.1177/1077801213487056

Geraghty, K.A., \& Woodhams, J. (2015). The predictive validity of risk assessment tools for female offenders: A systematic review. Aggression and Violent Behavior, 21, 25-38.

Gehring, K. S., Van Voorhis, P., and Bell, V. R. (2010). "What works” for female probationers? An evaluation of the Moving On program. Unpublished report: University of Cincinnati. 
Retrieved from

https://www.uc.edu/content/dam/uc/womenoffenders/docs/MOVING\%20ON.pdf

Gobeil, R., Blanchette, K., \& Stewart, L. (2016). A meta-analytic review of correctional interventions for women offenders: Gender-neutral versus gender-informed approaches. Criminal Justice and Behavior, 3, 301-322. doi:10.1177/0093854815621100

Golder, S., Engstrom, M., Hall, M. T., Higgins, G. E., \& Logan, T. K. (2015). Psychological distress among victimized women on probation and parole: A latent class analysis. American Journal of Orthopsychiatry, 85, 382-391. doi:10.1037/ort0000057

Green, B.L., Miranda, J., Daroowalla, A., \& Siddique, J. (2005). Trauma exposure, mental health functioning and program needs of women in jail. Crime and Delinquency, 51, 133-151. doi:10.1177/0011128704267477

Greenberger, D., \& Padesky, C.A. (2016). Mind over mood: Change how you feel by changing the way you think ( $2^{\text {nd }}$ ed.). New York: The Guilford Press.

Hamby, S. (2016). Self-report measures that do not produce gender parity in intimate partner violence: A multi-study investigation. Psychology of Violence, 6, 323-335. doi: 10.1037/a0038207

Harner, H. M., Budescu, M., Gillihan, S. J., Riley, S., \& Foa, E. B. (2015). Posttraumatic stress disorder in incarcerated women: A call for evidence-based treatment. Psychological Trauma: Theory, Research, Practice, and Policy, 7, 58-66. doi:10.1037/a0032508

Herie, M.A., \& Watkin-Merek, L. (2006). Structured relapse prevention: An outpatient counselling approach ( $2^{\text {nd }}$ ed.). Toronto, ON: Centre for Addiction and Mental Health. Herman, J. L. (1992). Trauma and Recovery: The Aftermath of Violence. New York: Basic Books. 
Hermann, B. A., Hamblen, J., Bernardy, N. C., \& Schnurr, P. P. (2014). Evaluating the evidence for PTSD-SUD treatment In P. Ouimette \& J. P. Read (Eds.). Trauma and substance abuse: Causes, consequences, and treatment of comorbid disorders (2nd ed.) (pp. 233252). Washington, DC: American Psychological Association.

Hilton, N. Z., Harris, G. T., \& Rice, M. E. (2010). Risk assessment for domestically violent men: Tools for criminal justice, offender intervention, and victim services. Washington, DC: American Psychological Association.

Holtfreter, K., \& Wattanaporn, K., A. (2014). The transition from prison to community initiative: An examination of gender responsiveness for female offender reentry. Criminal Justice and Behavior, 41, 41-57. doi:10.1177/0093854813504406

Hussain, N., Sprague, S., Madden, K., Hussain, F., Pindiprolu, B., \& Bhandari, M. (2015). A comparison of the types of screening tool administration methods used for the detection of intimate partner violence: A systematic review and meta-analysis. Trauma, Violence, \& Abuse, 16, 60-69. doi:10.1177/1524838013515759

Johnson, K., \& Lynch, S. (2013). Predictors of maladaptive coping in incarcerated women who are survivors of childhood sexual abuse. Journal of Family Violence, 28, 43-52. doi:10.1007/s10896-012-9488-3

Johnson, D. M., \& Zlotnick, C. (2007). Utilization of mental health treatment and other services by battered women in shelters. Psychiatric Services, 58, 1595-1597. doi: 10.1176/ps.2007.58.12.1595

Kail, B. L. (2010). Motivating women with substance abuse and intimate partner violence. Journal of Social Work Practice in the Addictions, 10, 25-43. doi:10.1080/15332560903526002 
Kraanen, F.L., Vedel, E., Scholing,A., Emmelkamp, P.M.G. (2014). Prediction of intimate partner violence by type of substance use disorder. Journal of Substance Abuse Treatment, 46, 532-539. doi:10.1016/j.jsat.2013.10.010

Kubiak, S. P. (2004). The effects of PTSD on treatment adherence, drug relapse, and criminal recidivism in a sample of incarcerated men and women. Research on Social Work Practice, 14, 424-433. doi:10.1177/1049731504265837

Kuijpers, K. F., van der Knaap, L. M., \& Winkel, F. W. (2012). PTSD symptoms as risk factors for intimate partner violence revictimization and the mediating role of victims' violent behavior. Journal of Traumatic Stress, 25, 179-186.

Lockwood, E., \& Forbes, D. (2014). Posttraumatic stress disorder and comorbidity: Untangling the Gordian knot. Psychological Injury and Law, 7, 108-121. doi:10.1007/s12207-0149189-8

Lovins, L. B., Lowenkamp, C. T., Latessa, E. J., \& Smith, P. (2007). Application of the risk principle to female offenders. Journal of Contemporary Criminal Justice, 23, 383-398. doi:10.1177/1043986207309437

Lynch, S. M., Fritch, A., \& Heath, N. M. (2012). Looking beneath the surface: The nature of incarcerated women’s experiences of interpersonal violence, treatment needs, and mental health. Feminist Criminology, 7, 381-400. doi:10.1177/1557085112439224

Lynch, S. M., Heath, N. M., Mathews, K. C., \& Cepeda, G. J. (2012). Seeking safety: An intervention for trauma-exposed incarcerated women? Journal of Trauma and Dissociation, 13, 88-101. doi:10.1080/15299732.2011.608780 
Macy, R. J., \& Goodbourn, M. (2012). Promoting successful collaborations between domestic violence and substance abuse treatment service sectors: A review of the literature. Trauma, Violence, and Abuse, 13, 234-251. doi:10.1177/1524838012455874

MacDonald, M. (2013). Women prisoners, mental health, violence and abuse. International Journal of Law and Psychiatry, 36, 293-303. doi:10.1016/j.ijlp.2013.04.014

Macy, R. J., Renz, C., \& Pelino, E. (2013). Partner violence and substance abuse are intertwined: Women’s perceptions of violence-substance connections. Violence Against Women, 19, 881-902. doi:10.1177/1077801213498208

Mahoney, A., Chouliara, Z., \& Karatzias, T. (2015). Substance Related Offending Behaviour Programme (SROBP): An exploration of gender responsivity and treatment acceptance issues for female prisoners. The Journal of Forensic Psychiatry \& Psychology, 26, 798823.

Matheson, F. I., Brazil, A., Doherty, S., \& Forrester, P. (2015). A call for help: Women offenders’ reflections on trauma care. Women \& Criminal Justice, 25, 241-255. doi: $10.1080 / 08974454.2014 .909760$

McKee, S.A. (2017). Concurrent substance use disorders and mental illness: Bridging the gap between research and treatment. Canadian Psychology, 58, 50-57.

McKee, S. A., Harris, G. T., \& Cormier, C. A. (2013). Implementing residential integrated treatment for co-occurring disorders. Journal of Dual Diagnosis, 9, 249-259. doi: $10.1080 / 15504263.2013 .807073$ 
McLellan, A.T., Luborsky, L., Woody, G.E., \& O'Brien, C.P. (1980). An improved diagnostic evaluation instrument for substance abuse patients: The addiction severity index. Journal of Nervous and Mental Disease, 168, 26-33. doi:10.1097/00005053-198001000-00006

Messing, J. T., Thaller, J., \& Bagwell, M. (2014). Factors related to sexual abuse and forced sex in a sample of women experiencing police-involved intimate partner violence. Health and Social Work, 39, 182-191.

Meyer, J. P., Wickersham, J. A., Fu, J. J., Brown, S., Sullivan, T. P., Springer, S. A., \& Altice, F. L. (2013). Partner violence and health among HIV-infected jail detainees. International Journal of Prison Health, 9, 124-141.

Miller, W. R., \& Rollnick, S. (2013). Motivational interviewing: Preparing people to change. ( $3^{\text {rd }}$ ed.). New York, NY: Guilford Press.

Mills, K. L., Teeson, M., Back, S. E., Brady, K. T., Baker, A. L., Hopwood, S., ...Ewer, P. L. (2012). Integrated exposure-based therapy for co-occurring posttraumatic stress disorder and substance dependence. Journal of the American Medical Association, 308, 690-699. doi:10.1001/jama.2012.9071

Minieri, A. M., Staton-Tindall, M., Leukefeld, C., Clarke, J. G., Suratt, H. L., \& Frisman, L. K. (2014). Relationship power as a mediator of intimate partner violence and mental health issues among incarcerated, substance-using women. International Journal of Offender Therapy and Comparative Criminology, 58, 303-319. doi:10.1177/0306624X12472017

Morrissey, J. P., Jackson, E. W., Elllis, A. R., Amaro, H., Brown, V. B., \& Najavits, L. M. (2005). Twelve-month outcomes for trauma-informed interventions for women with cooccurring disorders. Psychiatric Services, 56, 1213-1222. doi:10.1176/appi.ps.56.10.1213 Mueser, K. T., Noordsy, D. L., Drake, R. E., \& Fox, L. (2003). Integrated treatment for dual 
disorders: A guide to effective practice. New York: The Guilford Press.

Najavits, L. M. (2009). Psychotherapies for trauma and substance abuse in women: Review and policy implications. Trauma, Violence, \& Abuse, 10, 290-298. doi:

$10.1177 / 1524838009334455$

Najavits, L. M., \& Hien, D. (2013). Helping vulnerable populations: A comprehensive review of the treatment outcome literature on substance use disorder and PTSD. Journal of Clinical Psychology, 69, 433-479. doi:10.1002/jclp.21980

Nathanson, A. M., Shorey, R. C., Tirone, V., \& Rhatigan, D. L. (2012). The prevalence of mental health disorders in a community sample of female victims of intimate partner violence. Partner Abuse, 3, 59-75.

Norman, S. B., Myers, U. S., Wilkins, K. C., Goldsmith, A. A., Hristova, V., Huang, Z., ... \& Robinson, S. K. (2012). Review of biological mechanisms and pharmacological treatments of comorbid PTSD and substance use disorder. Neuropharmacology, 62, 542551. doi:10.1016/j.neuropharm.2011.04.032

Nosen, E., Littlefield, A. K., Schumacher, J. A., Stasiewicz, P. R., \& Coffey, S. F. (2014). Treatment of co-occurring PTSD-AUD: Effects of exposure-based and non-trauma focused psychotherapy on alcohol and trauma cue-reactivity. Behaviour Research and Therapy, 61, 35-42. doi:10.1016/j.brat.2014.07.003

Nowotny, K. M., Belknap, J., Lynch, S., \& DeHart, D. (2014). Risk profile and treatment needs of women in jail with co-occurring serious mental illness and substance use disorders. Women \& Health, 54, 781-795. doi:10.1080/03630242.2014.932892

O'Doherty, L. J., Taft, A., Hegarty, K., Ramsay, J., Davidson, L. L., \& Feder, G. (2014). Screening women for intimate partner violence in healthcare settings: Abridged Cochrane 
systematic review and meta-analysis. British Medical Journal (Clinical research ed.), 348:g2913. doi:10.1136/bmj.g2913

Perez, S., Johnson, D. J., \& Wright, C. V. (2012). The attenuating effect of empowerment on IPV-related PTSD symptoms in battered women living in domestic violence shelters. Violence Against Women, 18, 102-117. doi:10.1177/1077801212437348

Peters, R. H., Wexler, H. K., \& Lurigio, A. J. (2015). Co-occurring substance use and mental disorders in the criminal justice system: A new frontier of clinical practice and research. Psychiatric Rehabilitation Journal, 38, 1-6. doi:10.1037/prj0000135

Peterson, K. (2013). Learned resourcefulness, danger in intimate partner relationships, and mental health symptoms of depression and PTSD in abused women. Issues in Mental Health Nursing, 34, 386-394.

Resick, P. A., \& Schnicke, M. K. (1993). Cognitive processing therapy for rape victims: A treatment manual. Newbury Park, CA: Sage.

Rettinger, L. J., \& Andrews, D. A. (2010). General risk and need, gender specificity, and the recidivism of female offenders. Criminal Justice and Behavior, 37, 29-46. doi:10.1177/0093854809349438

Riger, S., Bennett, L. W., \& Sigurvinsdottir, R. (2014). Barriers to addressing substance abuse in domestic violence court. American Journal of Community Psychology, 53, 208-217.

Ritter, K., Kivisto, A., Handsel, V., \& Moore, T. (2014). Intimate partner violence PTSD, and substance use. In P. Ouimette \& J. Read (Eds.), Trauma and substance abuse (pp. 211230). Washington, DC: American Psychological Association.

Roberts, N. P., Roberts, P. A., Jones, N., \& Bisson, J. I. (2015). Psychological interventions for post-traumatic stress disorder and comorbid substance use disorder: A systematic review 
and meta-analysis. Clinical Psychology Review, 38, 25-38.

doi:10.1016/j.cpr.2015.02.007

Sacks, J. Y. (2004). Women with co-occurring substance use and mental disorders (COD) in the criminal justice system: A research review. Behavioral Sciences and the Law, 22, 449466.

Sacks, S., Chaple, M., Sacks, J. Y., McKendrick, K., \& Cleland, C. M. (2012). Randomized trial of a reentry modified therapeutic community for offenders with co-occurring disorders: Crime outcomes. Journal of Substance Abuse Treatment, 42, 247-259. doi: 10.1016/j.jsat.2011.07.011

Sacks, J. Y., Sacks, S., Mckendrick, K., Banks, S., Schoeneberger, M., Hamilton, Z.,... Shoemaker, J. (2008). Prison therapeutic community treatment for female offenders: Profiles and preliminary findings for mental health and other variables (crime, substance use and HIV risk). Journal of Offender Rehabilitation, 46, 233-261. doi:10.1080/10509670802143680

Salisbury, E. J. (2015). Program integrity and the principles of gender-responsive interventions assessing the context for sustainable change. Criminology \& Public Policy, 14, 329-338. doi:10.1111/1745-9133.12131

Saunders, J. B., Aasland, O. G., Babor, T. F., dela Fuente, J. R., \& Grant, M. (1993). Development of the alcohol use disorders identification test (AUDIT): WHO collaborative project on early detection of persons with harmful alcohol consumption-II. Addiction, 88, 791-804. 
Schaufenbil, R. J., Kornbluh, R., Stahl, S. M., \& Warburton, K. D. (2015). Forensic focused treatment planning: A new standard for forensic mental health systems. CNS Spectrums, 20, 250-253. doi:10.1017/S1092852915000152

Scott, C. K., Dennis, M. L., \& Lurigio, A. J. (2015). Comorbidity among female detainees in drug treatment: An exploration of internalizing and externalizing disorders. Psychiatric Rehabilitation Journal, 38, 35-44. doi:10.1037/prj0000134

Seedat, S., Stein, M. B., \& Forde, D. R. (2005). Association between physical partner violence, posttraumatic stress, childhood trauma, and suicide attempts in a community sample of women. Violence and Victims, 20, 87-98. doi:10.1891/0886-6708.2005.20.1.87

Simmons, C. A., Whalley, A., \& Beck, J. G. (2014). Use of mental health screening instruments by non-medical helping professionals: A needs assessment. Journal of Interpersonal Violence, 29, 2068-2090. doi:10.1177/0886260513516386

Skinner, H. A. (1982). The drug abuse screening test. Addictive Behavior, 7, 363-371.

Straus, M. A., Hamby, S. L., Boney-McCoy, S., \& Sugarman, D. B. (2006). The Revised Conflict Tactics Scale (CTS2). Journal of Family Issues, 17, 283-316. doi: $10.1177 / 019251396017003001$

Sullivan, T. P., \& Holt, L. J. (2008). PTSD symptom clusters are differentially related to substance use among community women exposed to intimate partner violence. Journal of Traumatic Stress, 21, 173-180. doi:10.1002/jts.20318

Sullivan, T. P., Weiss, N. H., Flanagan, J. C., Willie, T. C., Armeli, S., \& Howard, T. (2016). PTSD and daily co-occurrence of drug and alcohol use among women experiencing intimate partner violence. Journal of Dual Diagnosis, 12, 36-42. doi: $10.1080 / 15504263.2016 .1146516$ 
van Dam, D., Vedel, E., Ehring, T., \& Emmelkamp, P. M. G. (2012). Psychological treatments for concurrent posttraumatic stress disorder and substance use disorder: A systematic review. Clinical Psychology Review, 32, 202-214. doi:10.1016/j.cpr.2012.01.004

Van Voorhis, P., Wright, E. M., Salisbury, E., \& Bauman, A. (2010). Women’s risk factors and their contributions to existing risk/needs assessment: The current status of a genderresponsive supplement. Criminal Justice and behavior, 37, 261-288.

doi:10.1177/0093854809357442

Warshaw, C., Sullivan, C. M., \& Rivera, E. A. (2013). A systematic review of trauma-focused interventions for domestic violence survivors. National Centre on Domestic Violence, Trauma and Mental Health. Retrieved from http://www.nationalcenterdvtraumamh.org/wpcontent/uploads/2013/03/NCDVTMH_EBPLitReview2013.pdf

Weathers, F. W., Blake, D. D., Schnurr, P.P., Kaloupek, D. G., Marx, B. P., \& Keane, T. M. (2013). The Clinician-administered PTSD scale for DSM-5 (CAPS-5). Interview available from the National Center for PTSD at www.ptsd.va.gov.

Weathers, F. W., Litz, B. T., Keane, T. M., Palmieri, P. A., Marx, B. P., \& Schnurr, P.P. (2013). The PTSD checklist for DSM-5 (PCL-5). Retrieved from http://www.ptsd.va.gov/professional/assessment/adult-sr/ptsd-checklist.asp

Weir, B., O’Brien, K., Bard, R., Casciato, C., Maher, J., Dent, C., Dougherty, J., \& Stark, M. (2009). Reducing HIV and partner violence risk among women with criminal justice system involvement: A randomized controlled trial of two motivational interviewingbased interventions. AIDS and Behavior, 13, 509-522. doi:10.1007/s10461-008-9422-0 
Wright, E. M., Van Voorhis, P., Salisbury, E. J., \& Bauman, A. (2012). Gender-Responsive lessons learned and policy implications for women in prison: A review. Criminal Justice and Behavior, 39, 1612-1632. doi: 10.1177/0093854812451088

Yalch, M. M., Levendosky, A. A., Bernard, N. K., \& Bogat, G. A. (2015). Main and moderating influence on temperament traits on the association between intimate partner violence and trauma symptoms. Journal of Interpersonal Violence. Advanced online publication. doi: $10.1177 / 0886260515596978$

Ziedonis, D. M., Smelson, D., Rosenthal, R. N., Batki, S., Green, A. I., Henry, R. J., . . Weiss, R. D. (2005). Improving the care of individuals with schizophrenia and substance use disorders: Consensus recommendations. Journal of Psychiatric Practice, 11, 315-339. doi: 10.1097/00131746-200509000-00005.

Zlotnick, C., Najavits, L. M. Rohsenow, D. J., \& Johnson, D. M (2004). A cognitive-behavioral treatment for incarcerated women with substance abuse disorder and posttraumatic stress disorder: Findings from a pilot study. Journal of Substance Abuse Treatment, 25, 99-105. 
Table 1.

Summary of Critical Findings

1. IPV victimization is associated with substance use, PTSD, and their co-occurrence.

2. Among female offenders, substance use and PTSD are associated with IPV victimization and with measures of other mental illness, but treatment for these disorders is uncommon for women in the justice system.

3. There is empirical evidence supporting integrated therapeutic interventions for substance abuse and PTSD.

4. Trauma resulting from IPV victimization may be a criminogenic need or responsivity factor within a gender-informed Risk-Need-Responsivity model of offender treatment. 
Table 2.

Implications for Research, Policy, and Practice

\section{Research Gaps}

- Development and evaluation of theory and interventions for substance use and PTSD among IPV victims

- Follow-up research to assess the role of PTSD in increasing women's risk of criminal recidivism

- Identification of the benefits and limits of integrated treatment for female offenders

Policy Directions

- Routine assessment of substance use and PTSD symptoms for women using IPV support services

- Continued use of Risk-Need-Responsivity model and related risk assessments for female offenders, with incorporation of IPV and PTSD as potential treatment needs and responsivity factors

- Commitment to implementation of evidence-based interventions with fidelity

Practice Needs

- Capacity to provide services for, or increase access to, addictions and mental health treatment supporting IPV victims in shelters

- Integrated treatments for female offenders with co-occurring disorders including:

o Initial screening and ongoing assessment of SUD, PTSD, and IPV victimization

o Seeking Safety as a first-stage intervention for co-occurring SUD and PTSD

o Exposure/CBT for stage-two intervention where needed

o Transitional support for re-entry into the community

- Evaluation of interventions to contribute to the evidence base of integrated treatments for female offenders 